\title{
Traditional Practices and Perceptions of Epilepsy among people in Roma communities in Bulgaria
}

\author{
Plamen Antimov a , Ivailo Tournev a,b, Sashka Zhelyazkova a, \\ Josemir W. Sander ${ }^{c, d^{*}}$
}

${ }^{\text {a }}$ Department of Neurology, Medical University, Sofia, Bulgaria

${ }^{b}$ Department of Cognitive Sciences and Psychology, New Bulgarian University, Sofia, Bulgaria

${ }^{c}$ Department of Clinical and Experimental Epilepsy, UCL Queen Square Institute of Neurology, London WC1N 3BG and Chalfont Centre for Epilepsy, Chalfont St Peter SL9 ORJ, United Kingdom

d. Stichting Epilepsie Instellingen Nederland (SEIN), Achterweg 5, 2103 SW Heemstede, Netherlands

*Corresponding author:

Prof Ley Sander,

Box 29,

UCL Queen Square Institute of Neurology,

33 Queen Square,

London WC1N 3BG, UK.

E-mail:1.sander@ucl.ac.uk. 


\begin{abstract}
Purpose: We attempted to identify cultural aspects of epilepsy among the Roma community in Bulgaria by elucidating cultural beliefs, traditional treatments, and potential markers of stigma.

Methods: We established representative discussion groups among five distinct Roma subgroups (Lom, Kalderas, Thracian Tinsmiths (Tinkers), Kyustendil Xoroxane and Kopanari) from different Bulgarian regions. Data about local beliefs and treatment strategies were gathered.

Results: Most people were familiar with convulsions but non-convulsive focal seizures were seen not as epileptic but mainly as a "mental problem". Beliefs about putative etiologies for epilepsy were not uniform as some considered environmental and external factors such as high environmental temperatures, electric shocks, loud music, and fever as causes of seizures while others listed bad experiences, stress, trauma, fear and fright as possible causes. Epilepsy was seen by some as a divine punishment or resulting from black magic. Most considered epilepsy shameful and an obstacle to children attending school. Despite local differences, there was a uniform belief that epilepsy is incurable by Western medicine and people usually resort to traditional healers. A variety of rituals performed by local healers to treat epilepsy were described.

Discussion: Misconceptions about epilepsy may contribute to stigmatization in this population; this may in turn contribute to a high treatment gap in this group. As a result, the majority of Roma children with epilepsy leave school early, are greatly limited in their choice of spouse (particularly girls), and marriages often occur between people with epilepsy or those with a family history of epilepsy.
\end{abstract}

Keywords: alternative treatments, stigma, cultural believes, traditional healers 


\section{Introduction}

Over the centuries many myths have been associated with epilepsy, probably due to often brief but sometime dramatic symptoms followed by a rapid and seemingly miraculous recovery. In many societies, epilepsy has been attributed to possession by evil spirits or demons [1,2]. There is still stigma surrounding epilepsy, particularly in less educated communities [3].

The Roma (Gypsies), a particularly disadvantaged transnational ethnical minority, nomadic in the past, are a conglomerate of genetically isolated founder populations of common origin who have split into multiple groups [4]. Historical records describe many conflicts between settled and nomadic groups, such as the Roma, who have often been repressed and mistrusted, thus reinforcing their alienation and distrust of outsiders [5].

Over the last two decades, we have conducted field studies within the Roma community in Bulgaria, including a large door-to-door survey covering most of the Roma population investigating neuropathies. We found a considerably higher prevalence of neuropathies in the Roma population than in the general population. Genetic studies have shown considerable differences in the frequencies of mutations in different Gypsy populations [6]. During this work we encountered many people with different forms of epilepsy which, together with previous observations of familial forms of epilepsy in the Roma community, suggested a higher prevalence of epilepsy amongst them. We also observed that seizures in these communities were usually untreated and that focal seizures with sensory, autonomic or psychic symptoms were often not recognized as epileptic in nature.

We have since described several syndromes in people of Roma ethnicity, affected by different forms of epilepsy [7-10]. Most Roma are part of large extended families and consanguineous marriages are common [12]. In some groups almost half of weddings are between relatives. There have been suggestions of a high prevalence of epilepsy in some Roma communities and a significant treatment gap, particularly as traditional healers are often the chosen providers of epilepsy care.

Ethnographic data regarding traditional practices for epilepsy in Bulgaria is limited. Traditional healing practices for epilepsy have previously been ascertained among indigenous groups in Africa [13-26], and in Latin America. These included the Tzeltal Maya people in Mexico [27], the Kamayuráin in Brazil [28], the Uru-Chipaya people in Bolivia [29], and the Guarine people in Venezuela [30-32]. Epilepsy seen as a voodoo spirit possession was described in Haiti [33]. Understanding of epilepsy among traditional healers in rural Zambia was elucidated using focus groups [34]. Traditional healing practices for epilepsy in Kilifi, Kenya and in Bobo-Dioulasso, Burkina Faso have also been reported [35,36]. Treatment of epilepsy with herbs, acupuncture, and massage is common in Chinese traditional medicine $[37,38]$.

Our observations and previous anecdotal reports suggested high epilepsy stigma in the Roma community. The fear of being stigmatized may deter people from seeking medical care; this may be partly responsible for the large number of people who seem untreated in these communities. The perception of this treatment gap was a major determinant of the need for an assessment of cultural aspects of epilepsy and its treatment in the Roma community, as the 
findings may help designing programs to decrease this gap. A summarized account of the Roma communities in Bulgaria is provided in Appendix 1.

\section{Methods}

We established representative discussion groups in five main Roma subgroups in Bulgaria [4,39-41]. Of the various possible groups, we specifically selected well-defined, traditionoriented ones, characterized by markedly closed community structures, strict endogamy, and cultural characteristics and with whom we had established good relations during previous studies. We held a meeting within each discussion group to seek the community perceptions of epilepsy as well as to elucidate local traditional treatment practices for epilepsy. These groups included people with epilepsy and family members, prominent community leaders and community elders as they are usually familiar with local customs and traditional ways of treatment (table 1).

The study was reviewed and ethically approved by the Medical University Sofia Research Ethics Committee prior to initiation.

\begin{tabular}{|c|c|c|c|c|c|c|c|}
\hline & $\begin{array}{l}\text { Health } \\
\text { mediators }\end{array}$ & PWE & $\begin{array}{l}\text { Family } \\
\text { members }\end{array}$ & $\begin{array}{l}\text { Community } \\
\text { leaders }\end{array}$ & $\begin{array}{l}\text { Community } \\
\text { elders }\end{array}$ & Women & Men \\
\hline $\begin{array}{l}\text { Xoroxane } \\
\text { Roma } \\
\text { blacksmiths } \\
\text { in } \\
\text { Kyustendil }\end{array}$ & 3 & 4 & 8 & 2 & 8 & 13 & 12 \\
\hline $\begin{array}{l}\text { Xoroxane } \\
\text { and } \\
\text { Wallachian } \\
\text { Roma in } \\
\text { Lom }\end{array}$ & 4 & 3 & 8 & 3 & 7 & 13 & 12 \\
\hline Kalderas & 2 & 2 & 6 & 2 & 9 & 10 & 11 \\
\hline Kopanari & 2 & 3 & 6 & 3 & 9 & 11 & 12 \\
\hline $\begin{array}{l}\text { Thracian } \\
\text { tinsmiths }\end{array}$ & 2 & 2 & 5 & 2 & 9 & 10 & 10 \\
\hline
\end{tabular}

Table 1. Composition of the groups

Legend: PWE: People with epilepsy

Community representatives were invited by local community health mediators who also participated in the discussion groups together with at least one of the authors (PA and/or IT). Each of the five groups had between 20 and 25 participants and were held in a community setting - usually the local health center. This group size was chosen to represent the 
heterogeneity of the local population and to have representatives from different social and educational backgrounds. Each discussion group lasted between two to four hours to allow all participants to express their views and perceptions. Detailed notes were taken during workshops by one of the authors (PA or IT); due to privacy requirements only members of the research team had access to the discussion records.

The first discussion took place in the Roma neighborhood (Mahalla) of Kyustendil where most are from the Xoroxane subgroup. Traditionally, they followed Islam but more recently adopted Christianity and many are now Adventists. The second was held in the town of Lom which has four Roma neighborhoods. Those in the neighborhoods of Stadiona and Momin Brod are from the subgroup of Tinsmiths, part of the Jerlii Roma group, and those in the neighborhoods of Mladenovo and Humata are Reshetars from the Wallachian group. People from all four neighborhoods attended. The third group was among Kalderas in the town of Dolni Dabnik. Kalderas are one of the most endogamous Roma subgroups. The fourth was with the Kopanari people from two regions - the Gabrovo region (villages of Dushevo and Batoshevo) and Veliko Tarnovo region (town of Zlataritsa). They are Orthodox and usually deny their Roma identity. The group also has a closed endogamic community. The fifth group consisted of Thracian Tinsmiths from the village of Katunitca near Plovdiv. This is the most nomadic and endogamous group, and most in this community have poor educational achievements.

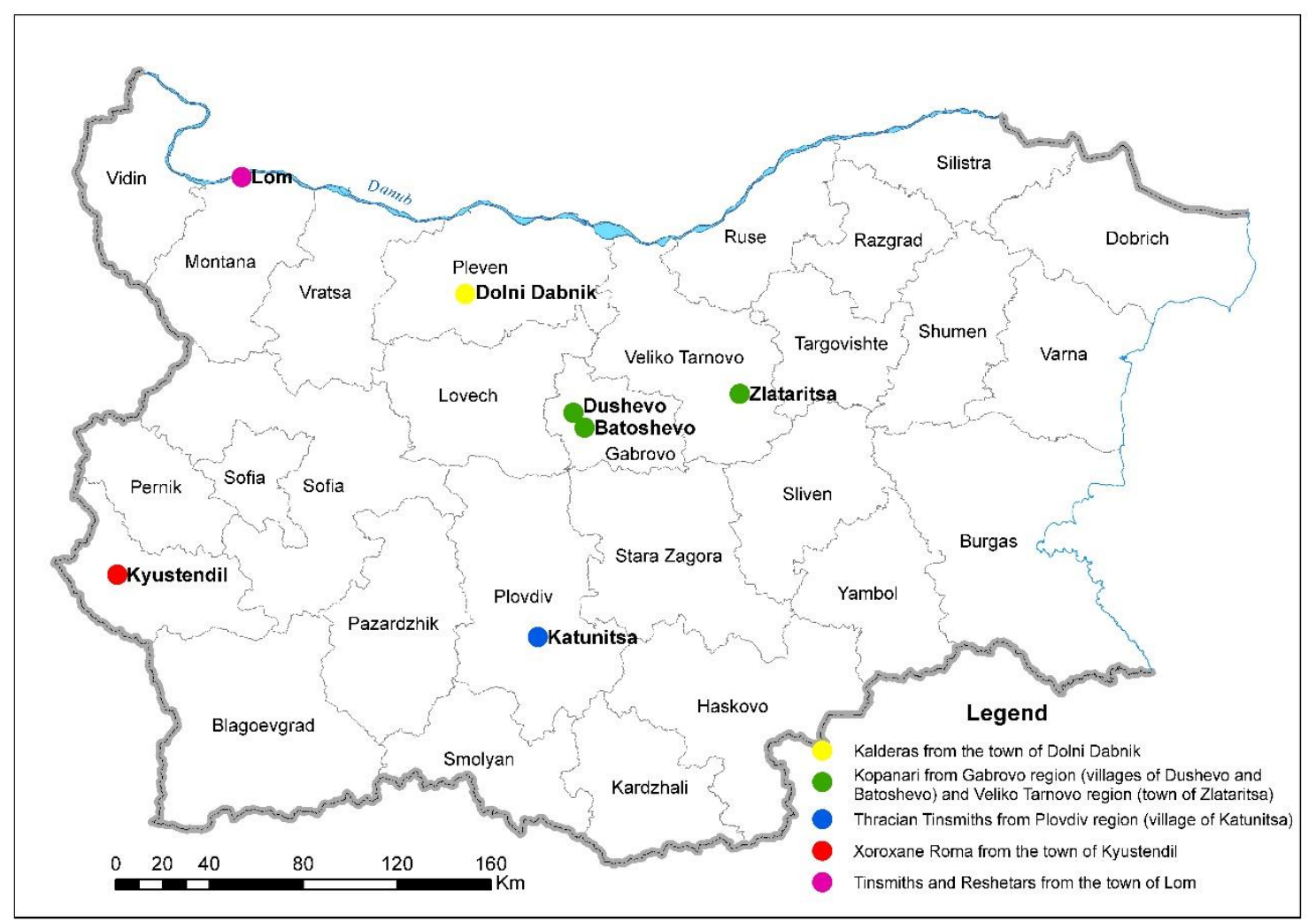

Fig. 1. A map of Bulgaria

At each group, moderated by one of the authors, epilepsy was discussed. After an initial introduction to epilepsy and explanation of the format of the meeting, an open discussion 
about the concept of epilepsy in their local culture followed. After this initial discussion, eight open-ended questions were presented and each openly debated. These questions were previously discussed and agreed with the health mediators to make them easily understood by the group participants, regardless of background. Five of the questions aimed to determine knowledge about epilepsy. Two questions aimed to obtain information about the burden of social stigma related to epilepsy. One question was developed to provide information about the traditional healing practices among Roma communities. All questions were explained to the participants and key terms clearly defined. For example, the term 'shameful' (in Romani "lazhavo") was defined as embarrassment about talking about their own epilepsy or about epilepsy in a family member to other people within their community. The Romani term most used for epilepsy is the word combination "perela bengendar", which means "thrown down by the devils" and the term is also used interchangeably with convulsions. Thracian Tinsmiths, however, are more likely to use "benga" for epilepsy while some Xoroxane Roma also use the term "hasarel pes".

The questions were as follows:

1. What are the manifestations of epilepsy?

2. Is it shameful to have epilepsy in your community?

3. Does epilepsy prevent children attending school?

4. Is epilepsy a disease of the soul or the brain?

5. Is epilepsy curable?

6. What causes epilepsy?

7. What are the local treatments for epilepsy?

8. For the final question, a putative focal seizure with automatisms was described in local terms and participants were then asked to name it. They were asked whether they would consider it to be epileptic in nature.

\section{Results}

Most of the participants were familiar with convulsions ("perela bengendar") but nonconvulsive focal seizures were not seen as epileptic. Lom, Kalderas, and Thracian Tinsmiths considered convulsive epilepsy as a disease of the brain while relatively equal groups of Kyustendil Xoroxane and Kopanari considered epilepsy to be a brain disease or a "mental problem".

Kyustendil Xoroxane considered "tensions" in life, "strong nerves", the environment in which they live, high environmental temperatures, the sun, fever, shock, loud music, and "dark forces" as causes of seizures. Lom Gypsies considered bad experiences, stress, trauma, "strong nerves", heredity, "high fevers in infants", fear and fright as causes. Kalderas considered epilepsy to be a divine punishment. Kopanari and Thracian Tinsmiths believed that epilepsy is a result of black magic, while the Tinsmiths believed it is the result of an 
"enchanted egg" lodged in the home of an individual. "Strong nerves" (in Romani "bare holya") is a term often used within the wider Roma community for episodes akin to temper tantrums but also used for events involving unusual behavior, particularly if accompanied by motor activity, facial expression and gestures suggesting that the individual concerned is disturbed.

All participants apart from the Kopanari considered epilepsy as shameful and an obstacle for children attending school.

A variety of rituals performed by local healers to treat epilepsy were discussed. Despite local differences, there was a belief that epilepsy cannot be cured by Western medicine and so people usually resort to traditional healers. The Kopanari and Thracian Tinkers, however, accepted that in some circumstances epilepsy could be treated using "modern drugs"; while Kalderas strongly believed it is only curable by traditional healing.

Results are summarized in table 2.

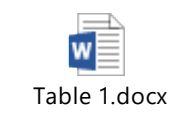

Table 2. Traditional beliefs about epilepsy among Roma in Bulgaria.

\subsection{Traditional views about epilepsy in Kyustendil}

Significantly, all participants from this community agreed that only convulsions are epileptic. There was unanimous agreement that it is shameful to have epilepsy. Along with the health aspects, they said that having epilepsy would mostly affect the individual's social life and would be associated with a much lower chance of getting married, and with being abandoned by their friends, suffering ridicule, and being feared by others. Most considered that children with epilepsy should not attend school; their relatives feared they could have a seizure in class. About half thought that epilepsy was a brain condition, and about half a spiritual condition. There was the same division of opinions about treatment and prognosis of epilepsy - some thought it was incurable, while others thought it could be treated with modern drugs. In this group, suggested causes of seizures included: "tensions" in life; "strong nerves"; the environment in which they live; high temperatures outside; the sun; fever; shock; loud music; a manifestation of the dark forces. The views expressed by people with epilepsy were similar to those of the others members of the group with little, if any, dissent.

Many people in this group stated that one must rely on God to cure the epilepsy but nevertheless advocated traditional treatments which, in this community, mostly involve rituals performed by local healers. There are many of these rituals including:

- For a first seizure, a nail is found quickly and hammered into the place first touched by the person's head at the time of the seizure; this is accompanied by the healer shouting "It shall stay here!"

- For a first seizure, the individual holds on to the trunk of a young tree. A healer then slits a hen's neck while chanting; the hen's blood is smeared on the individual's upper 
body. After this the epilepsy is deemed cured unless the tree dies or the person eats any chicken meat.

- For established epilepsy, a pillow is filled with hay while the healer chants. The pillow is then boiled, the person is sprinkled with the boiled water, and the pillow is thrown into the river. This ritual needs to be repeated three times.

- For established epilepsy, the healer clips a nail from the individual then scarifies the back of the neck and gives the individual a little of his own blood; the nail is then crushed and mixed with candle wax.

- For established epilepsy, at sunset the healer dresses the person in "enchanted" clothes; the individual then lies in a doorway with the head outside facing the sun. The healer chants to three red hot horseshoes, then puts them in a pot of water placed behind the individual's head; the ritual is repeated three times.

- For established epilepsy, an offering is made in which a black hen is slaughtered by the healer and a ritual dish is then made and given to be eaten by the widows in the community.

- For all types of epilepsy, a healing water is prepared by a healer who chants at the water in a spring until losing consciousness. The water is then thought to have healing powers, and people with epilepsy must drink from it.

Most thought that the described focal seizure was not an epileptic attack, but a manifestation of "strong nerves", of "madness" or of a "nervous breakdown" and the person having it needed to see a psychiatrist. The Romani words "delino" (crazy) and "halavdo" (referring to someone who does not know what he is doing) were mostly used.

\subsection{Traditional views about epilepsy in Lom}

Most participants considered convulsions to be epilepsy. Foaming at the mouth, shaking of the arms, and partial quivering of muscles were all considered manifestations of epilepsy. "Strong nerves" could also be a manifestation of epilepsy, but an attack of aggression would not.

Having epilepsy was considered shameful by most participants. They said that people with epilepsy hid their disease: single women "in order to marry" and in order to avoid the shame of others gossiping about them; young people hid it to avoid ridicule, being insulted or hurt. Participants thought that those with epilepsy were not always avoided by others but often isolated themselves as they did not want to be seen having a seizure. People here were more likely to send their children with epilepsy to school, but usually accompanied to the door by a parent or other relative. The majority of the participants thought that epilepsy was a brain disease and thought that some cases were treatable, but others not.

The suggested causes of seizures included: severe (bad) experience, stress, trauma, "strong nerves", heredity, high fevers in infants; some thought that fear can cause epilepsy while others denied this. Environmental factors suggested as influencing the occurrence of seizures were loud music, working with a computer, television games, and stress. Some blamed sins committed, or the devil. 
According to most, believing in God was the main treatment and people with epilepsy should read the Bible and pray regularly. Only one ritual was disclosed: a healer in the Mladenovo neighborhood melts a piece of lead which is then poured into cold water. The person with epilepsy must then sleep with the cast under the pillow for three nights, after which it is thrown it into the River Danube. This ritual was, however, not accepted by all and some, particularly in the Humata neighborhood, considered it sinful.

All participants characterized focal seizure as evidence of someone having "strong nerves" and most did not associate these with epilepsy.

\subsection{Traditional views of the Kalderas}

Kalderas called people with epilepsy "bengayle" and believed it was divine punishment for sins committed by their parents. They saw it as a disease of the soul and believed that people with epilepsy had abilities that set them apart - for example, qualities as mediums, a more highly developed sixth sense, an ability to anticipate certain future events - and are protected from other diseases. Kalderas believed that anyone who urinated in a location in which there were weasels would get epilepsy.

They described treatments for epilepsy. For example, when someone has a first seizure, the place where the fall occurred is dug up and the prognosis is predicted by the first object found, e.g. if they find a stone, the individual will be cured, whereas if coal is found, they will continue to have seizures. They often bury a living black cat at the exact location of the seizure. Kalderas also use different traditional treatment methods including infusions of herbs, chanting and casting of bullets by old women, and using the bones of a hen or a swallow which died on a nest as an amulet.

\subsection{Traditional views amongst the Kopanari}

The Kopanari group said that epilepsy is manifested only by convulsions and they do not consider it shameful and not a reason to stop children attending school. There was no common view about whether epilepsy is a disease of the brain or a spiritual condition. Most believed that the disease is treatable and that most can be treated with modern medication, in conjunction with traditional rituals. Older participants, however, thought that epilepsy is caused by black magic and is only cured by rituals.

A variety of rituals were described which apply to new seizures as well as to established epilepsy:

- The healer tears a piece of a cloth the person was wearing at the time of the seizure, and buries it where the person fell.

- The healer places a mirror against the person's body after a seizure and chants.

- A live snake or a live dove is ripped open by the healer and the person with epilepsy must swallow its heart

- The healer makes a briar wreath and slaughters a black hen. Rosehips are picked from a bush which grows in a field without shadows. A hole is dug up at the site where the individual fell at the first seizure and the wreath and the head of the black hen are then buried with the rosehips. 
- A live snake is boiled in water and later the water is poured over the person; where the water runs out, a nail is stuck to the ground.

The described focal seizure was considered by this group as events associated with "madness", or a "psychotic state", but not with epilepsy.

\subsection{Traditional views among Thracian Tinsmiths}

The participants in this group said that convulsions are the sole manifestations of epilepsy; epilepsy is a condition of the soul, shameful and hidden even from close relatives. Participants were almost unanimous in saying that children with epilepsy should not attend school. In this community, people are not able to marry if they have epilepsy or even if epilepsy is rumored. Most people from this group believed that epilepsy is treatable, but few individuals with epilepsy took medication - most relied on traditional treatment.

Epilepsy was believed to be caused by black magic from outside their community. They believed it was caused by an "enchanted egg" lodged in the home of the person with epilepsy by an outsider. The magic spell could be broken by taking the person with epilepsy's clothes, going to the cemetery, and burying them in someone's grave. Healers also picked certain herbs, burned them and scattered the ashes in the individual's home in the hope of covering the egg.

They considered the described focal seizure as a manifestation of "madness" or "possession by evil forces" and did not associate it with epilepsy.

\section{Discussion}

Ethnographic studies of epilepsy practices in resource-poor settings or in traditional communities are scarce. We investigated the perceptions of epilepsy and traditional healing practices among some Roma communities in Bulgaria.

Overall, most were aware of convulsions as epileptic events but were not aware of the epileptic nature of focal seizures. Most were also sentient of the neurological origin of epilepsy, with some exceptions, particularly amongst the Xoroxane and the Kopanari, who believed it was a spiritual state. Overall there was a positive view about the prognosis of epilepsy, as most considered it curable albeit using traditional treatments.

The different perceptions of the etiology of epilepsy were interesting. It seems that the more closed groups - Kalderas, Kopanari, and Thracian Tinsmiths - believed it is caused by black magic or supernatural forces, or blame it on outsiders. The Xoroxane and the Lom Roma mainly believed that environmental factors cause epilepsy, as well as having religious explanations. Hence, traditional rituals for seizure treatment in Kalderas, Kopanari, and Tinsmiths aimed to break the magic; such rituals were also available in less closed communities. Religiously-influenced Roma communities in Kyustendil and Lom used a variety of prayers as treatment.

Our observations suggest that the mythologizing of epilepsy is more common in the Wallachian Roma (such as Kalderas, Kopanari and Thracian tinkers) who are more likely to have lower education levels. Most groups considered epilepsy to be shameful and an obstacle 
to children attending school; the only exception was the Kopanari. Having epilepsy affects the person's social life and is associated with a lower chance of getting married, with being abandoned by their friends, with people gossiping about them; it also causes other people to fear them. Negative community perceptions of marriage of people with epilepsy have been reported from different locations [42-48]. People with epilepsy and their views may often be derided. They often isolate themselves, as epilepsy disrupts their social contacts, particularly children attending school and their contacts with other children. Negative attitudes towards children with epilepsy in school were previously reported in Saudi Arabia, Yemen and India amongst other places [49-53].

Widespread belief that epilepsy is not treatable by Western medicine causes these communities to resort to traditional healers. We have previously observed a lack of awareness among Roma about the importance of treatment adherence. Additionally, few people with epilepsy among the Roma community are known to the health services; most do not receive medical care and are mainly hidden within the community. These factors, together with stigma and fear of stigmatization, contribute to the high treatment gap.

As a result of stigma, many children with epilepsy in Roma communities do not attend school, or leave school early, and are greatly limited in their choice of spouse (particularly girls); thus marriages often take place between people with epilepsy or those with a family history of epilepsy which may lead to assortative mating.

Our approach to assessing perceptions and practices amongst these traditional communities has many limitations in scale and depth. Best practice would require intense observations of local practice and in-field immersion as this would lead to a better understanding of the reasoning behind the rituals. We had, however, frequently heard about many of these healing rituals and practices during previous field work in these communities, and had become familiar with some of the perceptions which were then fully elucidated during our discussions. Our findings should form the basis for more focused research in the future. Another limitation is that our discussion groups included both people with epilepsy and power groups (community elders and leaders) and this may have influenced some of the answers given by people with epilepsy given their fear of stigmatization. It was noticeable that the views of people with epilepsy were almost invariably in keeping with the majority. People with epilepsy were underrepresented in all groups, and limitations may also occur in participant contributions based on group size.

The Roma population is not homogeneous. It is subdivided into many different groups and subgroups. We selected five of the most closed and endogamous groups, as previous studies found the highest prevalence of monogenic inherited diseases in these groups. Groups that are well defined have specific traditions, customs, language, and are relatively infrequently mixed with individuals of other groups. They are not representative of the entire Roma community, which includes many other groups and this is a further limitation which does not allow for the generalization of our findings. Future studies are needed to elucidate many of the issues identified here and how they relate to other groups. 


\section{Appendix}

\section{The Roma community in Bulgaria}

European Roma are a heterogeneous population with a common origin and form a specific mosaic of diversified groups [54]. They are "a conglomerate of genetically isolated founder populations, with a complex pattern of genetic epidemiology" [55]. Whilst elements of different groups are in some aspects linked to each other, each group has its own individual characteristics and it is not possible to generalise characteristics from one specific group to the whole population. There are metagroups, groups and subgroups based on customs, traditional crafts, dialects and genetic differences. They originate in Northwest India [56] and their social structure and linguistics resembles the "Jatis" where the endogamous group, usually defined by profession, is the primary unit. The Roma migrated to Europe in three major streams; the majority settled in the Balkan provinces of the Ottoman empire, while some settled in the autonomous principalities of Wallachia and Moldavia, north of the Danube and others continued north and west. 
The Roma in Bulgaria consist mainly of those who originally settled south of the Danube with those migrating from Wallachia and Moldavia between the $17^{\text {th }}$ and $19^{\text {th }}$ centuries $[39,40,57]$. They belong to two metagroups: Jerlii and Wallachian. Each metagroup comprises many small groups which have different rules and endogamy [41].

In Bulgaria, the largest and most diverse Roma meta-group is the Jerlii, so called "sedentary Gypsies". They settled in Bulgaria earlier than the Wallachians. Most entered the country with the Ottoman army and there are two main subgroups: Dassikane (Christians) and Xoroxane (Muslims). Within Roma metagroup sub-divisions are large numbers of wellpreserved groups. Among Dassikane such groups are: chanters, colander makers, etc., and among Xoroxane: musicians, basket makers, lamplighters, traders, tinsmiths, blacksmiths, stove makers, and others. The boundaries of these subgroups have largely disappeared and only the two larger groups (Dassikane and Xoroxane) remain.

The second largest meta-group is the Wallachians which has a number of subgroups such as Kalderas, Kopanari, Thracian tinsmiths, Burgudjii, Wallach chanters, Grebenari and Lom Gypsies. Kalderas and Kopanari arrived in Bulgaria relatively later. The Kalderas were nomads but forced to settle in the 1950s. They usually live in small groups and profess Orthodox Christianity. Ethnonyms of this group often reflect their past professional expertise. The main form of marriage is "buying brides", a means of ensuring the stability of marriage, and commitment of the girl to the family to which she goes, and ultimately to provide endogamy. They have an "official" name for the public and a "Roma name", only used within their community. They build burial "tombs" furnished with a complete inventory. Their houses are usually lined with marble giving them a distinctive look [41]. Kalderas are the only Roma group that has its own forms of government. All disputes within the group are decided by the "meshere" council which represents all families, subgroups and regional divisions. Penalties are usually financial; the harshest punishment is banishment from the group [39].

Thracian tinker communities resemble those of Kalderas with similar lifestyles, keeping strict endogamy. They are distinguished by their distinct dialect. The Kopanari traditionally handcraft wood products such as bowls spindles, spoons and wooden bowls. They are strictly endogamous and mixed marriages are a rare exception.

The Lom Gypsies led a nomadic lifestyle until the end of the last century, when they arrived in Bulgaria from Serbia and settled in the city of Lom. They belong to the Wallachian group but have mainly lost their customs and traditions.

\section{Acknowledgements}

The authors would like to thank to Gail Bell for editorial assistance, A/Professor Penka Kastreva, for her assistance with Fig. 1, Dr Tara Maudold and Dr Sloan Mahone for their invaluable comments on previous versions of the manuscript. We are especially grateful to the health mediators Yanko Shiparov, Vasilka Aleksandrova, and Mancho Vanchev (Kyustendil), Tatiana Kirilova, and Anita Matinova (Lom), Eleonora Dimitrova (Zlatitsa), and Ognyan Kamenov from the Ethnic Minorities Health Problems Foundation who organized and managed the workshops. Lastly, we acknowledge Prof Luba Kalaydjieva for her work and for her unrelenting enthusiasm and commitment to health care in these communities. 
JWS is based at NIHR University College London Hospitals Biomedical Research Centre, which receives a proportion of funding from the UK Department of Health's Research Centres funding scheme. He receives research support from the Marvin Weil Epilepsy Research Fund, the UK Epilepsy Society, and the Christelijke Vereniging voor de Verpleging van Lijders aan Epilepsie, The Netherlands.

\section{Funding}

This work did not receive any specific grant from funding agencies in the public, commercial, or charitable sectors but our original epilepsy studies in these communities were supported by the National Health and Medical Research Council of Australia (Grant 458736).

\section{References}

[1] Daras MD, Bladin PF, Eadie MJ, Millett D. In: Engel J, Pedley TA, eds. Epilepsy: Historical Perspectives. In: Epilepsy: A Comprehensive Textbook. Philadelphia: Lippincott Raven Publishers; 1997:13-35.

[2] Einsberg L. Sociocultural Perspectives. In: Engel J, Pedley TA, eds. Epilepsy: A Comprehensive Textbook. Philadelphia: Lippincott Raven Publishers; 1997:41-44.

[3] WHO. Epilepsy: a public health imperative. 2019. WHO Publications; Geneva

[4] Gresham D, Morar B, Underhill PA, Passarino G, Lin AA, Wise C, Angelicheva D, Calafell F, Oefner PJ, Shen P, Tournev I, de Pablo R, Kucinskas V, Perez-Lezaun A, Marushiakova E, Popov V, Kalaydjieva L. Origins and divergence of the Roma (Gypsies). Am J Hum Genet. 2001; 69:1314-31.

[5] Zeman C, Depken D, Senchina D. Roma health issues: a review of the literature and discussion. Ethn Health 2003;8;223-49.

[6] Tournev I. Neuromuscular disorders in Roma (Gypsies) - collaborative studies, epidemiology, community-based carrier testing program and social activities. Neuromuscular Disorders 2016; 26: 94-103.

[7] Tournev I, Royer B, Szepetowski P, Guergueltcheva V, Radionova M, Velizarova R, Yonova M, Lathrop M, Jamali S, Petkov R, Raycheva M, Genton P. Familial generalized epilepsy in Bulgarian Roma. Epileptic Disord. 2007; 9:300-6.

[8] Angelicheva D, Tournev I, Guergueltcheva V, Mihaylova V, Azmanov DN, Morar B, Radionova M, Smith SJ, Zlatareva D, Stevens JM, Kaneva R, Bojinova V, Carter K, Brown M, Jablensky A, Kalaydjieva L, Sander JW. Partial epilepsy syndrome in a Gypsy family linked to 5q31.3-q32. Epilepsia. 2009; 50:1679-88.

[9] Azmanov DN, Zhelyazkova S, Dimova PS, Radionova M, Bojinova V, Florez L, Smith SJ, Tournev I, Jablensky A, Mulley J, Scheffer I, Kalaydjieva L, Sander JW. Mosaicism of a missense SCN1A mutation and Dravet syndrome in a Roma/Gypsy family. Epileptic Disord. 2010; 12:117-24. 
[10] Morar B, Zhelyazkova S, Azmanov DN, Radionova M, Angelicheva D, Guergueltcheva, V, Kaneva R, Scheffer IE, Tournev I, Kalaydjieva L, Sander JW. A novel GEFS+ locus on 12p13.33 in a large Roma family. Epilepsy Res. 2011; 97:198-207.

[11] Azmanov DN, Zhelyazkova S, Radionova M, Morar B, Angelicheva D, Zlatareva D, Kaneva R, Tournev I, Kalaydjieva L, Sander JW. Focal epilepsy of probable temporal lobe origin in a Gypsy family showing linkage to a novel locus on 7p21.3. Epilepsy Res. 2011; 96:101-8.

[12] Kalaydjieva L, Gresham D, Calafell F. Genetic studies of the Roma (Gypsies): a review. BMC Med Genet. 2001;2:5.

[13] Gerrits C.Epilepsy care in a non-clinical setting. A medical anthropological study among the Bassa and Kpelle in the rainforest of Liberia, West Africa. Tropical and Geographical Medicine. 1994; 46:S13-S17.

[14] Gessler MC, Msuya DE, Nkunya MH, et al. Traditional healers in Tanzania: sociocultural profile and three short portraits. J Ethnopharmacol 1995; 48:145-60.

[15] Hewson MG. Traditional healers in southern Africa. AnnInternMed 1998; 128:1029-34.

[16] Jilek-Aall L. Morbus sacer in Africa: some religious aspects of epilepsy in traditional cultures. Epilepsia 1999; 40:382-386.

[17] Puckree T, Mkhize M, Mgobhozi Z, et al. African traditional healers: what health care professionals need to know. Int J Rehabil Res 2002; 25:247-51.

[18] Reis R. Evil in the body, disorder of the brain. Interpretations of epilepsy and the treatment gap in Swaziland. Tropical and Geographical Medicine 1994; 46:S40-S43.

[19] Rwiza HT, Matuja WB, Kilonzo GP, Haule J, Mbena P, Mwang'ombola R, Jilek-Aall L. Knowledge, attitude and practice toward epilepsy among rural Tanzanian residents. Epilepsia 1993; 34:1017-1023.

[20] Stekelenburg J, Jager BE, Kolk PR, et al. Health care seeking behaviour and utilisation of traditional healers in Kalabo, Zambia. Health Policy 2005; 71:67-81.

[21] Tella A. The practice of traditional medicine in Africa. Niger Med J 1979; 9:607-12.

[22] Njamnshi AK, Bissek AC, Yepnjio FN, Tabah EN, Angwafor SA, Kuate CT, Déma F, Fonsah JY, Acho A, Kepeden MN, Azinwi YH, Kuwoh PB, Angwafor FF 3rd, Muna WF. A community survey of knowledge, perceptions, and practice with respect to epilepsy among traditional healers in the Batibo Health District, Cameroon. Epilepsy Behav. 2010; 17:95-102.

[23] Millogo A, Ngowi AH, Carabin H, Ganaba R, Da A, Preux PM. Knowledge, attitudes, and practices related to epilepsy in rural Burkina Faso. Epilepsy Behav. 2019; 95:70-74.

[24] Kpobi L, Swartz L, Keikelame MJ. Ghanaian traditional and faith healers' explanatory models for epilepsy. Epilepsy Behav. 2018; 84:88-92.

[25] Winkler AS, Mayer M, Ombay M, Mathias B, Schmutzhard E, Jilek-Aall L. Attitudes Towards African Traditional Medicine and Christian Spiritual Healing Regarding Treatment of Epilepsy in a Rural Community of Northern Tanzania. Afr J Tradit Complement Altern Med. 2010; 7: 162-170. 
[26] Osungbade KO, Siyanbade SL. Myths, misconceptions, and misunderstandings about epilepsy in a Nigerian rural community: implications for community health interventions. Epilepsy Behav. 2011; 21:425-9.

[27] Carod FJ, Vazquez-Cabrera C. A transcultural view of neurological and mental pathology in a Tzeltal Maya community of the Altos Chiapas. Revista de Neurologia 1996; 24:848-854.

[28] Carod-Artal FJ, Vazquez-Cabrera C. Neurological anthropology among the Kamayurá Indians of the alto Xingú. Revista de Neurologia 2001 32:688-695.

[29] Carod-Artal FJ, Vazquez-Cabrera CB. Ethnographic study of neurological and mental diseases among the Uru-Chipaya peoples of the Andean Altiplano. Revista de Neurologia $2005 ; 41: 115-125$.

[30] Carod FJ, Domenech E. [Treatment of epilepsy among the Guarine (Palenque) tribes]. Neurologia 1995; 9:394-395.

[31] Carod-Artal FJ, Vázquez-Cabrera CB. An Anthropological Study about Epilepsy in Native Tribes from Central and South America. Epilepsia, 2007; 48:886-893,

[32] Elferink JG. Epilepsy and its treatment in the ancient cultures of America. Epilepsia 1999; 40:1041-1046.

[33] Carrazana E, De Toledo J, Tatum W, Rivas-Vasquez R, Rey G, Wheeler S. Epilepsy and religious experiences: voodoo possession. Epilepsia 1999; 40:239-241.

[34] Baskind R, Birbeck G. Epilepsy care in Zambia: a study of traditional healers. Epilepsia 2005; 46:1121-1126.

[35] Kendall-Taylor N, Kathomi C, Rimba K, and Newton CR. Traditional Healers and Epilepsy Treatment on the Kenyan Coast. Epilepsia. 2008; 49: 1638-1639.

[36] Millogo A, Ratsimbazafy V, Nubukpo P, Barro S, Zongo I, Preux PM. Epilepsy and traditional medicine in Bobo-Dioulasso (Burkina Faso). Acta Neurologica Scandinavica 2004; 109:250-254.

[37] Lai C-W, Lai Y-HC. History of epilepsy in Chinese traditional medicine. Epilepsia. 1991; 32:229-302.

[38] Cai, L. () Traditional Chinese Herbal Medicine for Epilepsy Treatment Should Be Administered According to the Seizure Type and Epileptic Syndrome. Health 2017; 9:12111222.

[39] Marushiakova E, Popov V. Gypsies (Roma) in Bulgaria. In: Studien zur Tsiganologie und Folkloristik. Peter Lang, 1997 Frankfurt and Main, pp 15-122.

[40] Marushiakova E, Popov V, Kenrick D. Gypsies in the Ottoman Empire: a contribution to the history of the Balkans. 2001; Univ. of Hertfordshire Press.

[41] Tournev I. Clinical, genetic and epidemiological investigation of six neuromuscular disorders among the Roma people in Bulgaria. Doctoral Thesis 2001.

[42] Singh G, Selai C, Islam S, Chaudhary P, Sander JW. Marriage in epilepsy: The impact of the question in knowledge, attitude, and practice surveys. Epilepsy Behav. 2018; 85:164-172. 
[43] Li S, Chen J, Abdulaziz ATA, Liu Y, Wang X, Lin M, Qin Y, Liu X, Zhou D. Epilepsy in China: Factors influencing marriage status and fertility. Seizure. 2019; 71:179-184.

[44] Singh G, K Ganguly K, Banerji M, Addlakha R, Shah U, Tripathi M, Saxena V, Vohra H, Wakankar Y, Sharma M, Radhakrishnan K. Marriage in people with epilepsy: A compelling theme for psycho-behavioral research. Seizure. 2018; 62:127-130.

[45] Thabit MN, Sayed MA, Ali MM. Evaluation of knowledge about epilepsy and attitudes towards patients with epilepsy among university students in Upper Egypt. Epilepsy Res. 2018; 144:30-33.

[46] Chen J, Li Q, Tong X, Su M, Wang C, Zhou D. Epilepsy-related concerns among patients with epilepsy in West China. Epilepsy Behav. 2018; 82:128-132.

[47] Alamri S, Alghamdi A, Al Quait A. What Saudi teachers know about epilepsy: A crosssectional study of Tabuk City. Epilepsy Behav. 2018; 89:169-172.

[48] Shehata GA, Mahran DG. Knowledge and attitude of epilepsy among secondary schools students (epileptic and non-epileptic) in Assiut city Egypt. Epilepsy Res. 2011; 95:130-5.

[49] De Boer HM, Mula M, Sander JW. The global burden and stigma of epilepsy. Epilepsy Behav. 2008 May;12(4):540-6.

[50] Nuhu FT, Fawole1 JO, Babalola OJ, Ayilara OO, Sulaiman ZT. Social consequences of epilepsy: A study of 231 Nigerian patients. Annals of African Medicine 2010; 9;170-5

[51] Kaur J, Paul BS, Goel P, Singh G. Educational achievement, employment, marriage, and driving in adults with childhood-onset epilepsy. Epilepsy Behav. 2019; 97:149-153.

[52] Lee H, Lee SK, Chung CK, Yun SN, Choi-Kwon S. Familiarity with, knowledge of, and attitudes toward epilepsy among teachers in Korean elementary schools. Epilepsy Behav. 2010; 17:183-7.

[53] Al-Eryani B, Saied KG, Sharaf Alddin R, Al-Sobaihi S, Lutf W, Al-Taiar A. Knowledge of, attitudes toward, and perceptions of epilepsy among university students in Yemen. Epilepsy Behav. 2015; 52:102-7.

[54] Liegeois J-P. Roma, Gypsies, travelers. 1994; Council of Europe Press, Strasbourg.

[55] De Graaf P, Kalaydjieva L, Navarro C, Urtizberea A. “Editorial”. Acta Myologica. 2001; 20;177-178.

[56] Morar B, Gresham D, Angelicheva D, Tournev I, Gooding R, Guergueltcheva V, Schmidt C, Abicht A, Lochmüller H, Tordai A, Kalmár L, Nagy M, Karcagi V, Jeanpierre M, Herczegfalvi A, Beeson D, Venkataraman V, Carter KW, Reeve J, de Pablo R, Kučinskas V, and Kalaydjieva L. Mutation History of the Roma/Gypsies. Am J Hum Genet. 2004; 75: 596609.

[57] Marushiakova E, Popov V (). A History of the Roma of Bulgaria. Excerpted from The Gypsies of Bulgaria: Problems of the Multicultural Museum Exhibition. 1998; Patrin Web Journal. 